\title{
FURTHER DATA ON RESIDUES
}

\author{
L. J. MatThews \\ Research Division, Department of Agriculture, Hamilton
}

\section{Summary}

The effects of residues of various pelleted formulations of dieldrin, heptachlor, and DDT are considered for sheep and cattle pastures and for various components of these swards. An 8-week withholding period for dieldrin applied at $8 \mathrm{oz}$ a.i. per acre appears marginal. This is even more so with heptachlor where levels of its epoxide at 8 weeks were above $0.1 \mathrm{ppm}$ on a dry matter basis.

\section{EXPERIMENTAL}

TWO SERIES of trials were undertaken involving over a thousand analyses by gas/liquid chromatography. Pre-trial samples and herbage for dissection were taken on each site. All trials were replicated at least four times. All materials except where indicated replicated at least four times. All mat Chemicals Insecticide Notice. All rates are in a.i. per acre and residues are in parts per million ( $\mathrm{ppm}$ ) on a dry matter basis. The materials in all cases were applied by precision equipment.

\section{SERIES A: Comparison of DDT, DiEldRin aNd HePTACHLOR}

This series comprised a total of six trials laid down on sheep and cattle pastures and pure stands of white clover (Trifolium repens) at the Ruakura Agricultural Research Centre. The trials were in duplicate and on adjacent sites; the second series of three trials being laid down approximately a fortnight later than the first series of three trials. The sheep and dairy pastures were roughly $50 \%$ ryegrass (Lolium perenne) and $30 \%$ clover and $20 \%$ other grasses at time of laying down the first series of three trials. The percentage of clover had increased for the second series. Height of sheep swards was 1 to $2 \mathrm{in}$. and cattle swards 2 to 3 in. Individual rainfall is not given, but growth conditions were good to excellent throughout the period of the trials. All three insecticides were in the form of a prill (insecticide on outer surface of core). Sward samples were taken by hand clipping to a height of $1 / 2$ to $1 \mathrm{in}$. for analysis at times itemized in the following tables of results. Samples were taken at 2 or 4 weeks and precisely the same areas were recut four weeks later to give a sample of regrowth.

Series B: Comparison of DDT, Heptachlor and Dieldrin on Single SPECIES

Blocks of single species at the Marton Experimental Area comprising perennial ryegrass, Yorkshire fog (Holcus lanatus), Chewing's fescue (Festuca rubra var. fallax), browntop (Agrostis tenuis) and cocksfoot (Dactylis glomerata) were treated with heptachlor at 1 and $2 \mathrm{lb}$, dieldrin at 4 and $8 \mathrm{oz}$, and DDT at $2 \mathrm{lb}$. Two forms of materials were employed, a granule: (homogeneous mixture of 


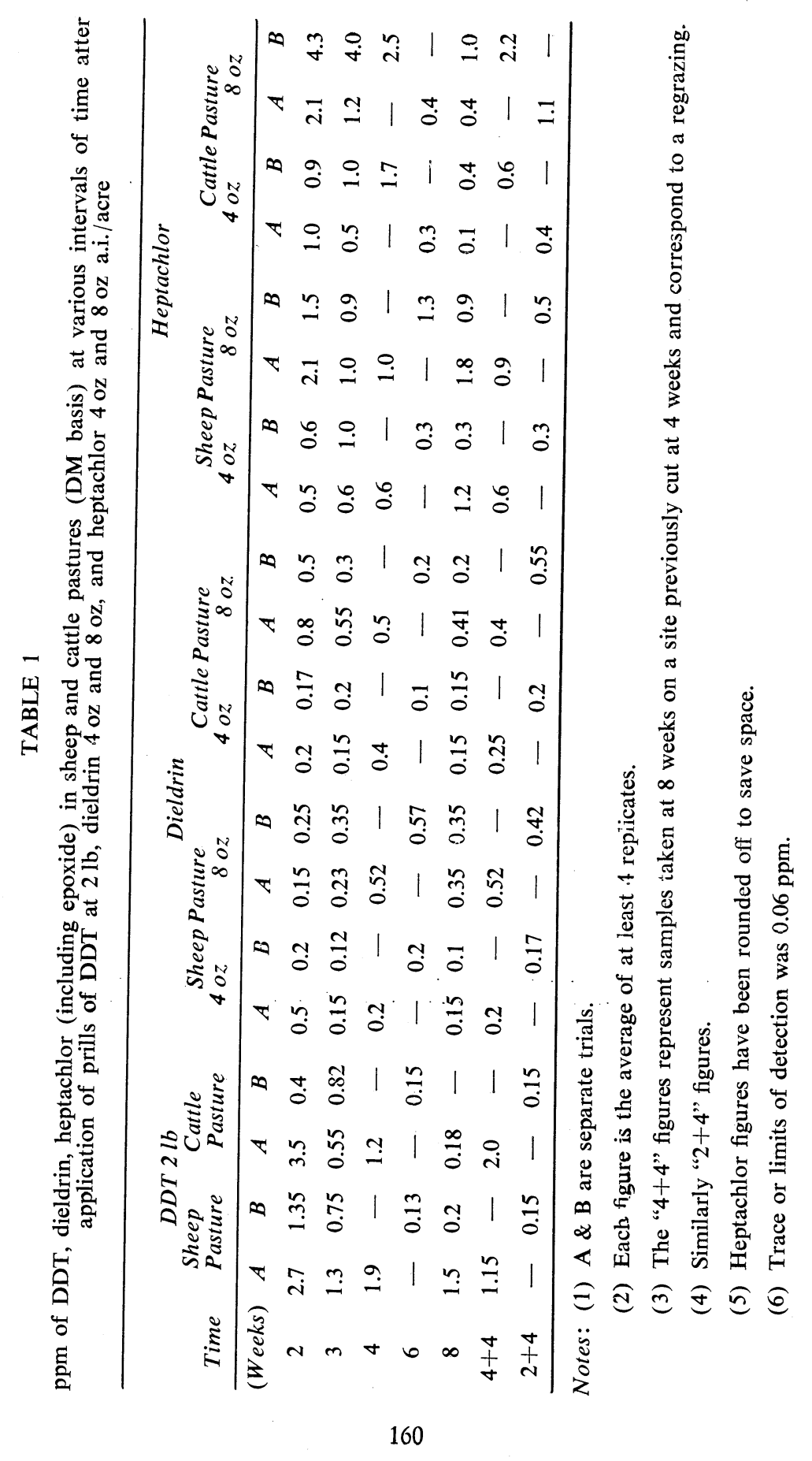


insecticide and carrier), and a prill type (insecticide on outer surface of central core), The granular formulations may not have surface of central of the A reicultural Chemicals Insecticide Notice. Analyses of two, four, eight, twelve and sixteen-week cuts on Angle species are available and will not be given in detail. DDT was the only treatment to give safe residue levels on all species at four weeks. At eight weeks dieldrin at $8 \mathrm{oz}$ was above $0.1 \mathrm{ppm}$ for all species. The level for Chewing's fescue was higher than for other species. The 16 weeks it was $0.3 \mathrm{ppm}$. Heptachlor and its epoxide species. At 16 weeks it $0.1 \mathrm{ppm}$ after 16 weeks and were $0.24 \mathrm{ppm}$ for $1 \mathrm{lb}$ and $0.4 \mathrm{ppm}$ for $2 \mathrm{lb}$ on Chewing's fescue.

\section{DISCUSSION}

In absence of statistical data, presenting the ranges of residue values probably would have been better than averaging mean values probably would have in view of findings (D. L. Harrison, values. Mean values are given in view of findings (D. L. Harrison, unpublished data) that the same amount of active ingredient irregular

cation. as both materials are considered residues and are taken into account when setting tolerance.

"Safe" intake levels of DDT, dieldrin and heptachlor by stock have not been evaluated fully under New Zealand conditions. Until these data are known, it is impossible to translate pasture residues into safe withholding periods. However, until further data are into safe withels of $1 \mathrm{ppm}$ for DDT for dairy pastures and $5 \mathrm{ppm}$ available, levels of $1 \mathrm{ppm}$ for DDT for for dieldrin and heptachlor DDT for sheep pastures and 0.1 ppm for dif then the following is evident from the sheep and dairy trials:

(1) Levels for DDT are generally safe for a 4-week withholding period for dairy stock and a 2-week withholding period for dry stock.

(2) An 8-week withholding period is marginal for $8 \mathrm{oz}$ of dieldrin and 5 weeks for $4 \mathrm{oz}$ is even more so.

(3) An 8-week withholding period is very marginal for $8 \mathrm{oz}$ of pelleted heptachlor and 5 weeks for $4 \mathrm{oz}$ even more so.

These data are substantiated for the trials on pure species. The degree of retention did not differ markedly except for Chewing's fescue, where the level at 16 weeks for $8 \mathrm{oz}$ of dieldrin was $0.3 \mathrm{ppm}$ and for 1 and $2 \mathrm{lb}$ heptachlor was 0.24 and $0.4 \mathrm{ppm}$. Yorkshire fog generally showed the lowest levels.

The data presented indicate there is evidence of systemic uptake or recontamination of the foliage, although probably there were or recontamination of ences in residue levels between $4+4$ week namples and the 8-week samples nor between the $2+4$ week and the 6-week sample. Results of levels in the soil before and after are not given in detail but DDT was present at higher levels in the 0 to $1 \mathrm{in}$. layer of soil. Heptachlor and heptachlor epoxide were present only in trace amounts (less than $0.06 \mathrm{ppm}$ ) or at levels prenceding $0.1 \mathrm{ppm}$. Dieldrin may have been present but would have been obscured by DDE.

No attempt is made to give the in vivo conversion of heptachlor to its epoxide on the plant tissues. On the sheep and dairy pastures heptachlor even at one week was present generally in lower amounts than its epoxide. For single species, in general, conversion to the epoxide was complete by the 12-week cut. 
Rainfall is not given in detail but growth conditions were excellent throughout the period of the trials, hence the results presented in this paper may not apply necessarily to poorer growing conditions.

\section{ACKNOWLEDGEMENTS}

My acknowledgements are due to Miss J. M. Ruddenklau and A. Thompson for conduct of field trials, the Superintendent, Seed Testing Station, for herbage dissection, Dr E. Pawson for chemical analysis, and the Superintendent, Biometrics Section, for statistical design of trials. I also wish to thank all other staff associated with the trials, and D. L. Harrison for his helpful comments. 